\title{
ADVANCED GAS TURBINES HEALTH MONITORING SYSTEMS
}

\author{
Marcin ADAMOWICZ ${ }^{1}$, Grzegorz ŻYWICA ${ }^{2}$ \\ ${ }^{1}$ Solar Turbines Europe S.A., adamowicz marcin@,solarturbines.com \\ ${ }^{2}$ Institute of Fluid Flow Machinery, Polish Academy of Sciences, Fiszera, 14, \\ 80-231 Gdansk, Poland, gzywica@imp.gda.pl
}

\begin{abstract}
An overview of science papers in the field of machine diagnosis has exposed increasing efforts in developing accurate and reliable engine health monitoring systems. Attempts have been made in both diagnostics and prediction of system faults. Essential limitations of the standard monitoring system are discussed in this paper as well as arguments for implementation of the Advanced Gas Turbine Health Monitoring Systems. Examples of implementation are discussed and a comparison between "Enhanced Arrangement" and "Standard Arrangements" is carried out. The individual system components are implemented today using very different methods. Performance degradation of gas turbines is described here with an approach of Condition Based Maintenance and it was shown how the classification method can help to improve equipment operation. The review of signal processing methods was carried out to present strengths and shortcomings of individual methods.
\end{abstract}

Keywords: monitoring, gas turbine, vibrations, artificial neural networks, predictive model.

\section{ZAAWANSOWANY SYSTEM MONITOROWANIA STANU TECHNICZNEGO W TURBINACH GAZOWYCH}

\section{Streszczenie}

Przegląd literatury w dziedzinie diagnostyki maszyn wykazuje duże zainteresowanie środowiska naukowego opracowaniem niezawodnych i precyzyjnych metod oceny stanu technicznego napędów turbinowych. Prace te mają najczęściej na celu opracowanie systemów służących do bieżącej diagnostyki uszkodzeń pojawiających się podczas pracy jak i prognozowania przyszłych defektów. W artykule przeprowadzono ocenę najczęściej stosowanych metod diagnostycznych jak również omówiono zastosowanie „Zaawansowanego systemu monitorowania stanu technicznego turbin gazowych”. Przedstawione zostało porównanie standardowego i zaawansowanego układu diagnostyczno-sterującego. Indywidualne metody diagnostyczne zostały opisane wraz z przykładami zastosowania. Wykazano, że spadek sprawności turbiny gazowej jest ściśle związany z jej stanem technicznym, który może być stale monitorowany. Oceniono również wpływ metod klasyfikacji uszkodzeń na wykrywalność stopnia degradacji.

Słowa kluczowe: monitorowanie, turbiny gazowe, wibroakustyka, sieci neuronowe, modele predykcyjne

\section{INTRODUCTION}

Gas turbines operate on the Brayton's thermodynamic cycle where air is compressed by an axial or a centrifugal compressor, and fuel is added which is then burnt in the combustor. The power turbine extracts work from the expanding gases propelling both the compressor and the shaft. Power turbine's work is used to drive compressor, generator, pump, etc. The main components of a gas turbine are: compressor, combustor and power turbine. They can be seen on a cutaway of the coldend drive gas turbine presented in Fig. 1 .

Gas turbines are widely used in industrial applications due to many advantages over other technologies such as: high reliability and availability, wide power range, clean energy production, low carbon oxides and nitrogen oxides emissions, fuel flexibility, exhaust gases can be reused for other processes, dense modular design, high power density, short construction time, low cost of generated power and short start-stop cycle time. These advantages over other technologies have led to a surge in new installations over the last couple of decades. There has been much progress made in gas turbine technologies. The pursuit of higher efficiency is driven by a higher compression ratio and increased turbine inlet temperature: ceramic coatings, superalloys, single crystal technology. Higher efficiency should go hand in hand with increased reliability and availability. 


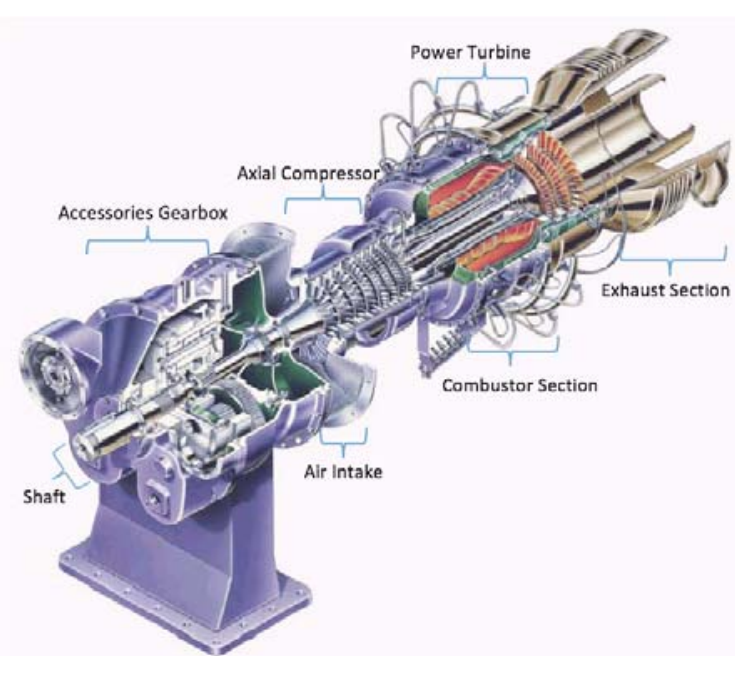

Fig. 1. Saturn 20 Gas Turbine from https://mysolar.cat.com

\section{ADVANCED GAS TURBINES HEALTH MONITORING ALGORITHM}

The term Advanced Gas Turbine Health Monitoring System is viewed in this paper as a system that monitors a machine and detects faults and predicts the performance degradation. Data mining is followed by performance evaluation and abnormal operation detection in search of prefailure symptoms. To perform the above functions effectively, the following requirements should be met [3]:

- system should be automated as much as possible in monitoring, system analysis and supporting decision making;

- robust against noisy signal and faulty information;

- wide range of detectable faults and adjustability to newly discovered faults which may not be initially reported;

- use existing instruments or as few new ones as possible;

- flexible, modular and open architecture allowing an easy adaptation to operator needs;

- user-friendliness so that unskilled personnel can use it with minimum training.

Additionally, the following elements must be implemented:

- $\quad$ acquisition of measurement data;

- evaluation of data to discard unreliable and faulty sensor readings;

- data processing to derive useful diagnostics information;

- management of historic data to maintain records of valuable information.

AGTHMS should monitor various parameters simultaneously such as Gas Path Analysis (GPA), vibration level, oil debris detection and engine actuators. A combination of different classifiers can be employed to improve fault verification. For example, in Fig. 2, high vibration level combined with oil debris low and high lube oil's differential temperature (difference between lube oil supply and drain bearing temperature) will execute a shutdown command confirming the abnormal bearing operation. Individual readings could give a false indication due to sensor or controller malfunction; however a combination of more than one readings can improve the decision-making algorithm. Merging information from different instruments will reduce the number of false trip alarms caused by a sensor malfunction. Moreover, equipment abnormalities can be detected before they develop into failure.

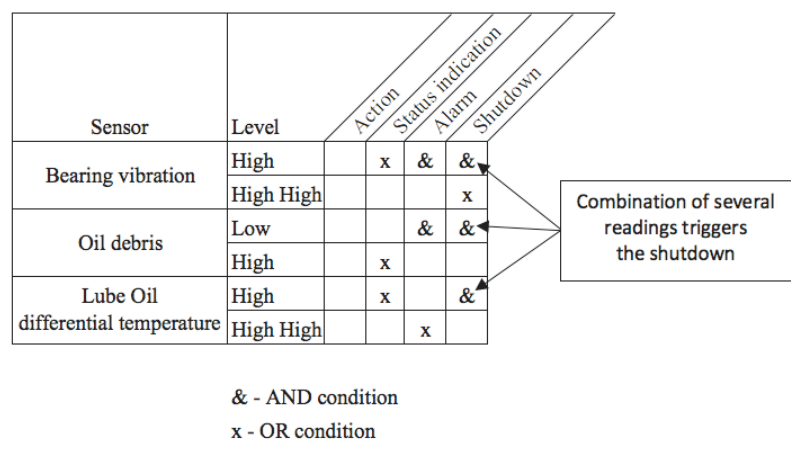

Fig. 2. Example of combine decision making algorithm

Gas turbines often utilize redundant sensors for monitoring critical parameters. However, this increases overall package cost and adds complexity to both electrical and mechanical systems. With AGTHMS it can be possible to monitor engine sensor health status indirectly by taking advantage of other readings. The simple example can be found in relationship between shaft's rotational speed and the first harmonic of the spectrum analysis from a proximity probe. In the example shown in Fig. 3, the first harmonic has a frequency of $167 \mathrm{~Hz}$, corresponding to a rotational speed of 10,000 revolutions per minute. When both the engine bearing and the sensor are healthy, readings should correlate but in case they do not a possible malfunction could be present and an alarm or shutdown should be initiated.

Analysing the vibration spectrum and comparing them with readings from a different sensor, such as a speed probe, can bring the following benefits:

- Sensor cross-check - increased system integrity level without the need for redundant sensors;

- Gas turbine alarm/shutdown counteraction is based on several rather than on a single reading.

\section{PROBLEM DEFINITION}

A typical arrangement of the main components in the engine health monitoring system usually takes into account monitoring such parameters as temperatures, pressures, flow parameters, vibration level and speed. These are passed to a digital controller which contains a set of pre-defined rules (i.e. If value $\mathrm{x}$ is less than $\mathrm{y}$ then engine " $O K$ " else 
send an alarm signal or shutdown engine safely). This is referred to as "Standard arrangement" in Fig. 4. It is sufficient for majority of engine operation. The fast digital controller can act upon rapid changing conditions allowing safe and efficient operation of the engine. The main advantages of this condition-based control are: an implementation simplicity and a straightforward modification procedure when necessary. However, it often lacks a prognosis value and a comprehensive diagnostics functionality as the majority of data which are analysed based on the pre-defined "IF-THEN" rules.

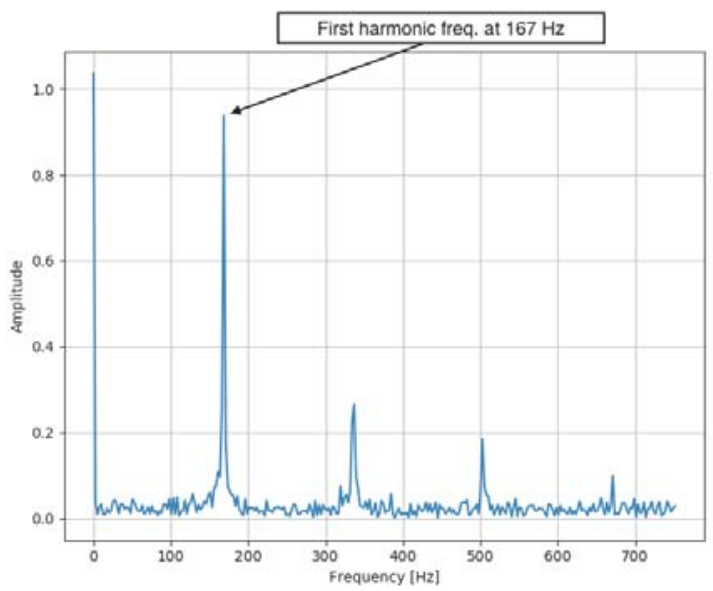

Fig. 3. Vibration spectrum measured using a displacement probe

More advanced diagnostics and prognostics require a new approach. "Enhanced arrangement" shown in Fig. 4, provides additional signal processing solely dedicated to engine health and performance monitoring. The key elements in this system are: Observer, Signal Decomposition \& Conditioning and Condition Assessment. Signal Decomposition \& Conditioning block can allow advanced processing of signals registered by vibration and displacement sensors. This preprocessing of raw data allows for an extraction of interesting features for a user in such a way that an incipient fault can be detected and acted upon before it develops into a failure. A further discussion on this subject can be found in part Vibration Monitoring of this paper.

The key feature of Enhanced Arrangement is to allow the self-condition assessment and do it effectively. Health classification algorithm, imbedded in Condition Assessment block, requires a residual between the measured and the predicted outputs. This forecast can be archived by Observer which consists of regression methods accurately predicting expected engine outputs for a given operating point (engine speed, load, temperature, etc.). Classification methods can employ expert knowledge to correctly label symptoms to a potential problem and make decision: whether to or not to continue engine operation, adjust setpoints, inform operator or shut down the engine.

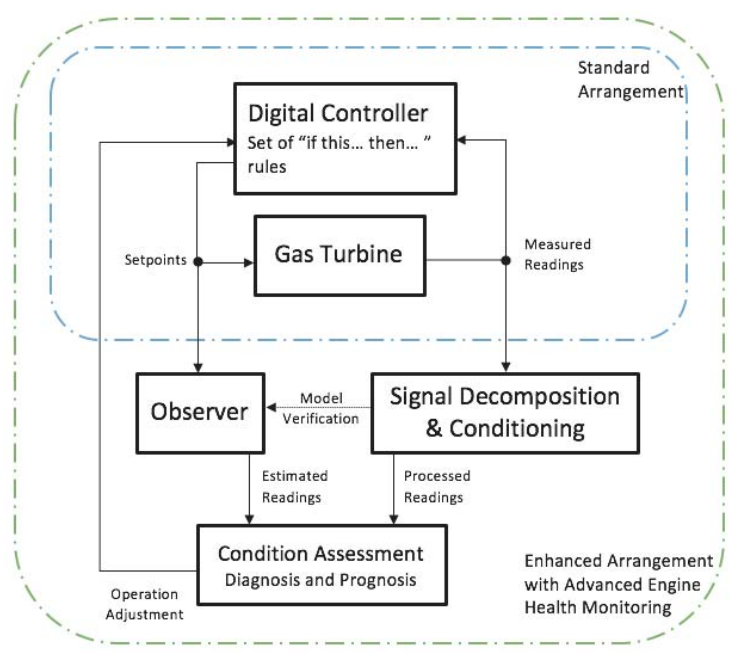

Fig. 4. AGTHMS Block Diagram

\section{OPERATION ADJUSTMENT}

The operation of a typical industrial gas turbine will be governed by a set of "IF-THEN" rules and tunable constants. These will vary engine to engine as no customer site is identical and the manufacturing tolerance of gas turbines require a number of specific settings to be tailored to individual units. These can include: inlet guide vane or bleed valve range, fuel starting schedule, fuel pressure at burner, engine shaft speed or pilot to main ratio for a low NOx emission engine and many more. A control system for a gas turbine should include parameters correction for a variation of an inlet temperature or a barometric pressure. This allows an on-line adjustment to the engine operation. However, in "Standard Arrangement", there are limitations in the self-adjusting capability as the control system uses "IF-THEN" rules. The self-adjusting ability of "Enhanced Arrangement" can be significantly increased. For example, a customer has received a different type of diesel fuel and now his engine is struggling to start on his liquid. Furthermore, the situation takes place in a remote location and the gas turbine manufacturing expert cannot mobilise himself on very short notice. In Fig. 6a the engine starts on liquid but fails to reach the minimum temperature in a defined time frame. An expert would probably adjust fuel command schedule for more aggressive behaviour. However, the personnel on-site are not qualified to carry out such modifications. AGTHMS could perform the system's auto-diagnostics as per Fig. 5. In the first stage, Condition Assessment block receives "Engine Failed to Reach TemperatureShutdown" alarm. 


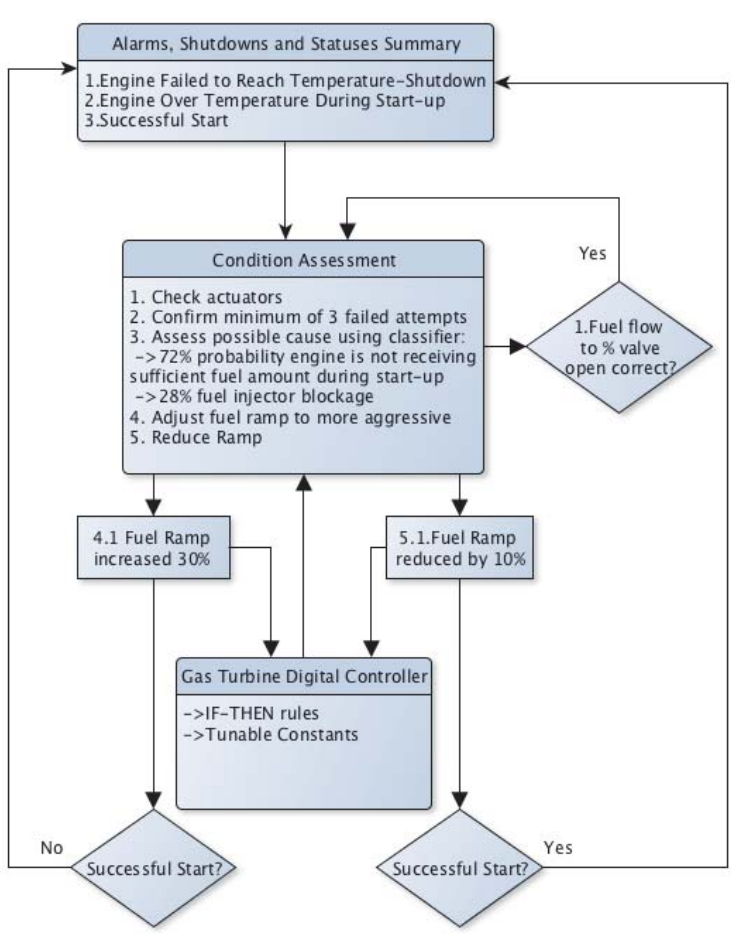

Fig. 5. Gas Turbine Fails to Ignite Troubleshooting using AGTHMS

The algorithm performs a basic condition check on the actuators to eliminate their malfunction. In the next step of the algorithm, the occurrence of a certain number of failed start attempts is required before classifier can be triggered. In this example, two main causes are rectified with a probability of $72 \%$ and $28 \%$ respectively. The algorithm takes a decision to change fuel ramp and another start is initiated as per Figure 5b. This time engine exceeds the maximum temperature setpoint during start-up. The fuel ramp is reduced and the engine starts successfully (see Figure 5c).

\section{RECALL VS PRECISION IN FAULT CLASSIFICATION}

Condition Assessment block is expected to accurately distinguish abnormal, leading to faults symptoms from the false ones. A selected classifier will usually have a trade-off between a high recall or a precision as per Fig. 7. These two evaluation classifiers can be defined as Eq. (1) and (2).

Recall $=\frac{\text { Genuine Faults }}{\text { Genuine Faults }+ \text { Not Detected Genuine Faults }}$

Genuine Faults

Precision $=\frac{\text { Genuine Faults }}{\text { Genuine Faults }+ \text { Healthy State Misclassified as Fault }}$

A high recall will lead to more false alarm (lower precision) detections. Making the system more sensitive to unusual operating conditions. It will be expected from this classifier to detect the majority of possible faults at expense of spurious

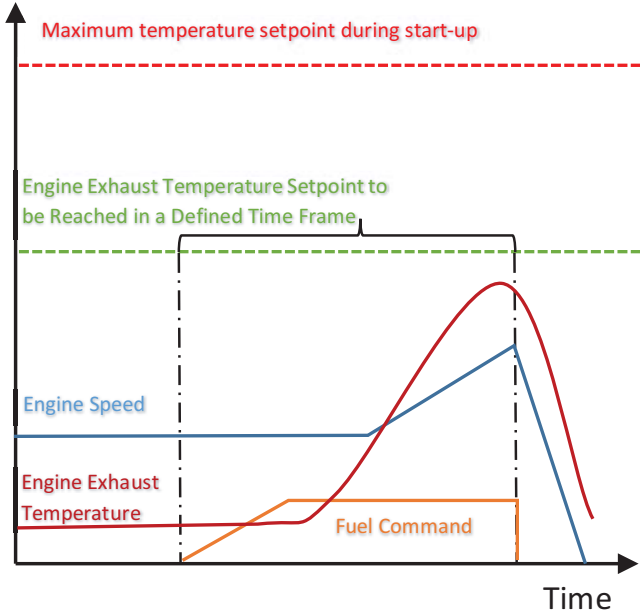

a) Failed to Reach Temperature

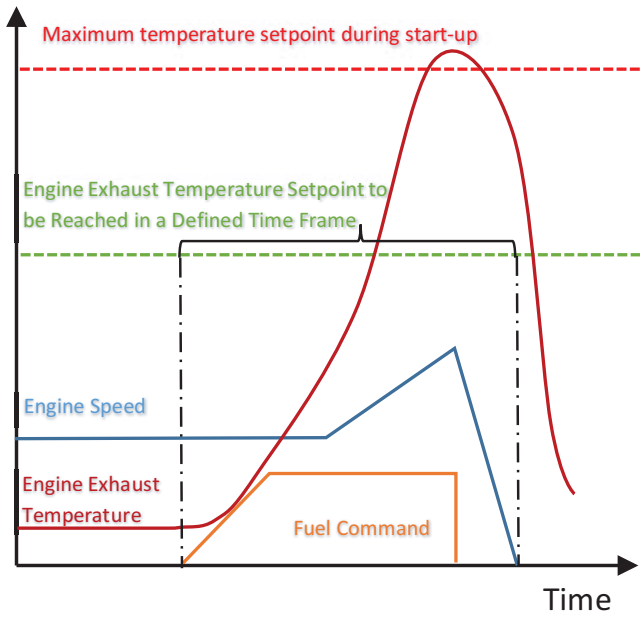

b) Over Temperature During Start-up

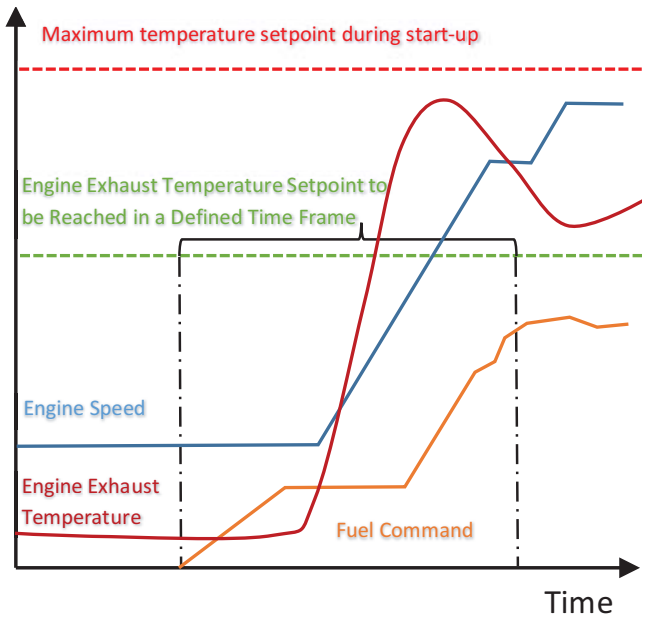

c) Successful start

Fig. 6. Gas Turbine Fuel Adjustment for Start-up

faults. On the other hand, a high precision classifier will be less sensitive to abnormal (lower recall) states but less prompt to a false failure detection. Depending on the fault scenario the high precision classifier (Fig. 7a) can be selected to make instantaneous counteraction such as engine shutdowns as it is going to be more robust to noise than high recall. In cases like the one shown in Fig. 
$7 \mathrm{~b}$, the high recall classifier can be effective in detecting symptoms, otherwise it would be missed by the precision focused classifier, therefore, the output from it should be analysed further by another algorithm or a system operator/an expert. Symptoms classified with high recall could be used with "Combined decision making" algorithm (see Fig. 2) where more than one cause is required for a counteraction.

\section{PROGNOSTICS AND DIAGNOSTICS}

From the above example, the main two functions of the AGTHMS are the diagnostics, which can be referred to as a function that detects present and past abnormalities, and the prognostics, which allows an estimation of the engine wear \& tear and a prediction of faults [1].

\subsection{Prognostics}

The capability to predict the health of a machine component over time is at the foundation of Condition Based Maintenance. It relies on the current health assessment and uses this information to plot the degradation curve of a component allowing for time to failure prediction [9]. The prognostic methods can be classified as data-driven and model-based.

- Data-driven prognostics

This approach relies on the assumption that statistical characteristics of the data are relatively unchanged unless the malfunction event occurs in the system [10-11]. Prognostics uses this approach for a statistical and learning technique from the theory of pattern recognition.

- Model-based prognostics

Using an accurate mathematical model, this check can be performed between its outputs and measurements from sensors. Residuals are calculated and their values are used to detect signs of the system's malfunction. However, this is more effective for smaller systems as an analytical approach requires a detailed quantitative mathematical model. For larger systems obtaining it can be expensive and time consuming [10].

- Knowledge-based prognostics

This type of prognostics can be made based on a causal analysis, expert systems and pattern recognition [10]. The first one is based on modelling fault-symptom relationships. Expert system can be formulated as IF-THEN rules, which mimics a troubleshooting that is done by an experienced engineer not requiring him to be present for consultation.

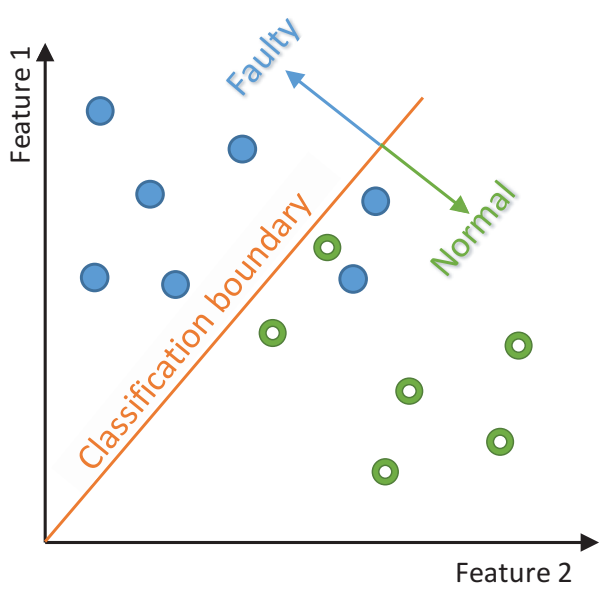

a) High precision but low recall

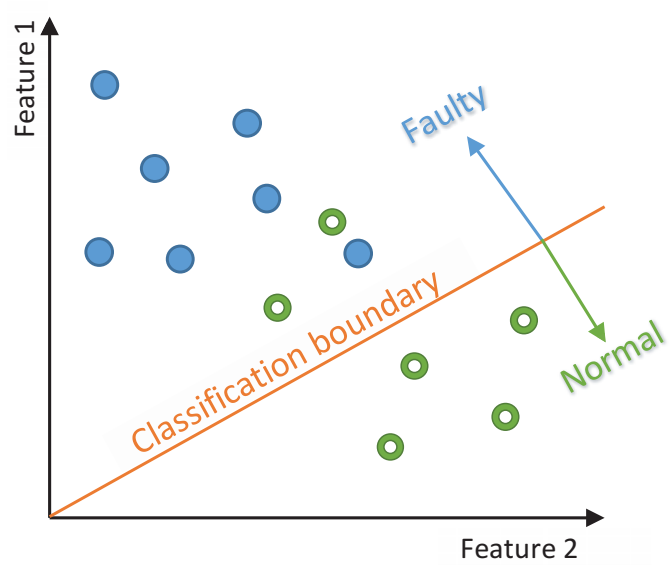

b) High recall but low precision

Genuine Fault Condition

( Healthy Condition

Fig. 7. Fault classifiers configuration

\subsection{Diagnostics}

This can be related to fault, abnormality or failure detection. The AGTHMS should allow an incipient fault detection. The severity of a fault will usually increase over time with the equipment usage. An early root cause analysis can reduce the impact of a fault on the system's operation. Detecting signs of the system's malfunction at an early stage can be used not only to plan an earlier part replacement, but also to change from the operation method. It can help to minimize the risk of an abnormality developing into a catastrophic failure at an early stage of the operation. For example, if the gearbox gear's excessive wear is detected using the vibration analysis the control system can reduce work extracted from the shaft which reduces the risk of a catastrophic failure of the gearbox as gears will work at lower forces. This may give the user extra time to order a replacement part and schedule an equipment shutdown for overhaul. 


\section{CONDITION BASED MAINTENANCE}

The concept of a condition based maintenance is well known in industry [2]. It proposes a maintenance regime based on the equipment condition rather than on the hourly operation schedule. Engine performance will deteriorate over time reducing the amount of work that can be extracted from the shaft. This will happen due to the reduced compressor efficiency. Air mass flow will decrease at designed compressor speed because of engine degradation. Sources of degradation in the engines are well known [5-7] (fouling, erosion, hot corrosion, internal liner surface cracking, increase in the tip and seal clearance, contamination, plugging of the injector and the cooling holes). The velocity of these processes will be different depending on the manufacturing tolerance and is strongly associated with the engine operating conditions such as the atmospheric conditions and the engine's operation regime (full or partial load, frequency of start \& stop cycles, type and quality of fuel). These variables would mean that degradation curves of two similar engines will never be identical and the maintenance based on the operation hours of the machinery is inaccurate, exposing user to avoidable costs, downtime and finally a reduced production. From the user's perspective, too frequent preventive maintenance inspections on the equipment can also have a negative effect on reliability [4] due to maintenance-induced faults.

The main advantages of this approach are a reduced operation cost and a higher availability as it allows operator to better plan maintenance.

A similar method of monitoring gas turbine performance can be applied to other equipment such as actuators if a sufficient number of sensors is available. Valves can be condition monitored not only to confirm if open/close transition is made in a designed time period but also to detect wear by establishing the trajectory of degradation (performance-versus-time plot) [1]. A valve used for the fuel flow control can be monitored for a deposit build-up due to impure fuel. This will affect flow thereby monitoring the pressure drop on this valve at a given percentage opening. If this relation deviates, too great an early scheduled overhaul should be performed before the valve fails.

\subsection{Gas Path Analysis}

This common method in evaluating AGTHMS relies on a thermodynamic analysis of the gas path and of the energy balance. Using existing sensors for: air/gas flow, atmospheric pressure, intake/exhaust temperature, combustion temperature spread, shaft's rotational speed and power generated on the shaft. This information could be used to detect: ineffective operation, compressor and turbine fouling, foreign object damage, filter clogging, plugged nozzles, worn seals, excessive blade and nozzles tip clearance.
This is based on an assumption that most fault in a gas turbine will show up or leave signature in the performance of the component exposed to the air/gas flow passing through the engine [1].

\subsection{Direct analysis of thermodynamic data}

The first step of the analysis is to observe the engine's output data under normal operating conditions at given speed and power [13]. The second step is to calculate deviations of the readings over time, providing both the magnitude and the rate of changes. The greatest advantage of this method is its straightforward implementation; however, this approach can help to rectify only the previous known faults. To overcome this drawback an additional implementation of the engine model, which has a fault simulation signature, is suggested.

\subsection{Adaptive simulation of the performance of a gas turbine}

Due to assembly or manufacture tolerances different engines of the same model will exhibit differences in their performance. Engine manufacture will guarantee minimum power and efficiency at ISO 3977-2 standard (temperature $15^{\circ} \mathrm{C}$, relative humidity $60 \%$ and ambient pressure at sea level). The authors of paper [14] propose an algorithm which calculates weight coefficients by comparing estimated values from analytical equations and engine readings. These coefficients are used for the first engine model and, later, by comparing the weight coefficient's rate of changes, allow monitoring the engine performance. Straight model (without adaptive coefficients) provides unreliable reading unlike the adaptive one.

\subsection{Statistical regression}

A nonlinear GPA method has been developed 12 to predict degradation of a gas turbine. This method employs statistical historical data from the engine performance to establish a degradation curve. It allows evaluating the current turbine's health as well as predicting its future health.

\subsection{Model-based estimations}

The Kalman filter (KF) algorithm can be suitable for estimating the engine state accurately 15. Using a feedback from the system outputs nulls the differences between the measurements and estimated values. Using the $\mathrm{KF}$ algorithm is an effective way to monitor engine performance degradation.

Limitations of this method are related to degreeof-freedom where the number of estimated parameters is greater than the number of independent measurements [1]. Production engine will have limited number of measurements done by sensors therefore accurate fault source identification is difficult. However, to overcome this problem, an approximation technique can be used. Another limitation of KF is a linear nature 
allowing an accurate estimation of a nonlinear system in a narrow linearized region.

A comparison was carried out by the authors of [24] between the KF and the Artificial Neural Network for the isolation of a single fault. Both methods achieve a good fault isolation accuracy with a slight bias towards KF, where the linear model is available with a reasonably accurate relation between inputs and output. The main advantage of KF over ANN is a simple reconfiguration to work on different measurement suites and with different fault configurations.

\subsection{Artificial neural network}

Artificial Neural Networks (ANN) have been a powerful tool in estimating gas turbines performance [17-27] and fault detection due to their ability to model highly nonlinear relationship such as fuel flow and shaft speed dynamics. They prove to have excellent approximation capabilities. An ANN with one hidden layer of sigmoidal or hyperbolic tangent activation function and output layer of linear unit is capable of approximating any continuous function [16]. Their excellent regression model ability can be used for an observer model as a part of the AGTHMS. On the other hand, where abnormal symptoms are found an ANN can be employed to classify the type of problem.

The authors of [17] prove that an ANN can be trained to have over $90 \%$ success rate in finding 15 different faults of Pratt and Whitney PW4000 engine. The neural network's ability to correctly predict output variables without any knowledge of equations governing the main phenomena from the system is investigated in [18]. A number of interesting conclusions are drawn in [19] where authors are using ANN techniques to simulate a plant with a cogeneration gas turbine unit. Providing effective plant optimization tools helps to reduce operation costs. In this paper, the ANN proves a good accuracy of estimation but also better calculation performance over the physical simulator. A stress control method employing an ANN is investigated in [20]. Data required to carry out network training in this instance is obtained from a fine element model as stress measurements on the turbine rotors are not available. The component or sensor fault diagnostics using an ANN is presented in [22]. The network exhibits a potential to be implemented as a part of the gas turbine monitoring and diagnostics system.

The advantage of an ANN utilized as observer (as shown in Fig. 4) over Standard arrangement can lay in its ability in teaching the complete relation between the engine operation and the actuators' states for a given operating state. For instance, a digital controller will monitor if the system completes the valve check during a start-up sequence, except it will only check a pre-defined conditions. Where ANN can be taught completely to work as a gas turbine operator. For example, which valve, switch levels etc., have to be set at a given operating point or a given period of time. Any deviation from a previously learned sequence can be detected, significantly reducing the troubleshooting time.

The main drawback of using this method in modelling a gas turbine is in their "black-box" nature; lack of transparency in humanunderstandable term [27]. In the "white-box" model where analytical equations describe the coefficient parameters correspond to the process and can be easily associated with the performance degradation. An optimal structure of the neural network for a given problem is generally unknown. Criteria for validating and training an ANN are generally not defined [25]. An inappropriate teaching method can provide poor generalization performance of the network. However, in recent years there has been much effort put in developing better training methods. The well-known back propagation algorithm, which utilizes a gradient-based algorithm, can be replaced by a learning algorithm called Extreme Learning Machine [26]. In this method, input weights and hidden biases are randomly selected but output weights are calculated by Moore-Penrose generated inverse. This method has proved to have better performance than the BP algorithm.

During the network design process there is a list of issues which needs to be carefully addressed such as data leakage, model-under or overfitting.

\subsection{Fusion systems}

These methods use more than one approach to deal with data analysis in order to combine straights from different methods simultaneously minimizing their drawbacks. A combination of a neural network and the fuzzy logic is demonstrated in [27]. In this publication, a much better known nature of the fuzzy logic is combined with the excellent approximation of a highly nonlinear system. The fuzzy logic on its own can prove to be problematic in selecting a correct fuzzy set to model a system or a fault [28]. However, its combination with a genetic algorithm (GA) can provide an effective automated procedure for designing a system based on the fuzzy logic since a GA is a very good search method. A combination of an ANN and a GA is presented in [21] where the first one is used to estimate the engine internal health and the second one is used for sensor bias detection and estimation. This approach exploits the ANN capability of estimating the behaviour of a strongly nonlinear system while improving the measurement robustness through a GA application.

A Mixture of an ANN, a KF, a statistical analysis and Bayesian/Evidence based decision making has improved the accuracy and the quality of diagnostics in [23] for an aircraft gas generator. This approach can be extended to improve assets management, predicting a machine component's life, work scopes, and inventory requirements. 
A combination of the empirical mode decomposition (EMD) method and an adaptive neuro-fuzzy interface system (ANFIS) model is proposed in [39]. The article describes how features are extracted from a signal using the EMD method and later analysed by the ANFIS model.

\section{VIBRATION MONITORING}

The vibration measurement system relies on a set of probes (displacement and velocity probes or accelerometers) and input conditioning modules to provide detailed information on equipment operation. Historically vibration amplitudes were measured at various locations (bearings, gearbox, engine shaft, engine case) and compared with alarm and shutdown thresholds [8].

With decomposition algorithms, a waveform data can be analysed in more depth. Three main categories are: time-domain analysis, frequencydomain analysis and time-frequency analysis [29].

\subsection{Time-domain analysis}

The methods from the first group mentioned above extract characteristics from time waveforms such as mean, peak, peak-peak, standard deviation, root mean square etc. Time Synchronous Average is a popular and simple technique which calculates a signal average of raw signal samples to remove or reduce noise, enhancing signal's interesting components. Another more advanced time-domain analysis found in literature is an autoregressive moving average method which models a signal using the following expression:

$x_{t}=a_{1} x_{t-1}+\cdots+a_{p} x_{t-p}+\varepsilon_{t}-b_{1} \varepsilon_{t-1}-\ldots-b_{q} \varepsilon_{t-q}$

In the above equation, $x_{t}$ is the analysed signal $a_{1}$ $\ldots a_{p}$ and $b_{1} \ldots b_{p}$ are coefficients and $\varepsilon_{t}$, $\varepsilon_{t-1 \ldots} \varepsilon_{t-q}$ are white noise error terms. By extracting these coefficients, signal features can be obtained. A comparison between the regular Fast Fourier Transform (FFT), Higher Order Spectra, and Autoregressive (AR) has been done in 30 on an electric motor with a broken bar and the AR model was exhibiting the best accuracy rate. However, as it is suggested in [29], problem with AR or autoregressive moving average models is difficult to solve due to the complexity of modelling, particularly in establishing the order in the model. Other time-domain methods exist, however, shall not be discussed here since this paper is not dealing with vibration diagnostics in greater detail.

\subsection{Fourier analysis}

The frequency-domain analysis converts timedomain data into frequency-domain data and allows to build a correlation between a particular frequency and a fault signature. The most popular algorithm is a FFT. This signal decomposition method allows conversion between the time and frequency domain and vice versa, using the wellknown Fourier transform (FT) method. Series of sine waves are subtracted from the original signal depending on their phase frequency and amplitude, and a spectrum is created. The most common methods are: power spectrum, frequency filters, envelope analysis and side band structure. The shortcoming of this method is a limitation on a signal, which can be transformed. It has to be stationary and linear (as combinations of all decomposed signals are periodical sine waves).

\subsection{Time-frequency analysis}

To overcome the stationarity limitation of the FFT, the Short Time Fourier Transform (STFT) method has been introduced which allows investigating a time-varying signal by moving a time window through this signal [31]. Since in a short duration the signal does not change significantly, it can be considered as stationary. However, the method lacks adaptivity due to a fixed length of the time window. If a better location in time of a higher frequency component is needed, the time window should be narrowed but on the other hand, to locate a lower frequency the window should be widened. Due to the Heisenberg uncertainty principle, the finest time location and the best frequency resolution cannot be reached at the same time. This transform is only suitable for quasi-stationary signals as small changes in frequency can be missed. For the health diagnostics of rotating equipment, the following methods quoted below are more suitable.

\subsection{Wavelet analysis}

Analogous to the STFT method, a signal is decomposed in a time window but a significant difference lays in the adaptive length of it and the form of wavelet which is used. Unlike in the STFT method where time-frequency distributions are used, in the Wavelet Analysis we have time-scale representations of the signal. This method has been widely used in the equipment fault diagnostics due to its ability to detect transient features, often related to abnormalities in rotating machinery. The adaptivity of this method makes it suitable for nonstationary signals [32]. For a higher frequency, the time window is made narrower allowing a good time location of the frequency component. However, a lower frequency resolution is achieved for a lower frequency but as a result, a better resolution of frequency is established with a poorer location in time. This is a trade-off between a frequency location in time and resolution. To overcome this issue, the Wavelet Packet Transform method was developed which works by decomposing a signal into multiple quasi-bands and decomposing them iteratively, leading to a better time and frequency resolution for all bands. There is a difficulty in selecting the most suitable wavelet to match the signature of a signal. 
The Continuous Wavelet Transform (CWT) method in a vibroacoustical diagnostics of a gearbox operated with variable speed is investigated in [37] confirming CWT good ability to deal with the signal signature detection for faults and an ability to work under non-stationary conditions where often a single abnormality can have an amplified effect.

The advantage of the wavelet analysis over the FT method is presented in [38] where authors investigate the loose blade detection in a gas turbine. The CWT method can detect the number and positions of faulty blades which is never possible by using only the FT method.

\subsection{Wigner-Ville Distribution and pseudo- distributions}

The Wigner-Ville Distribution (WVD) is one of the oldest time-frequency analysis methods. It offers a high time-frequency resolution nevertheless it suffers from cross-term interferences and spectrums can have frequencies with negative energy. The Cohen's class distribution [34] is a modified method which allows maintaining high time-frequency resolutions while suppressing the cross-term interferences of the WVD method at the expense of the reduced time-frequency resolution.

Lockhed-Martin company uses the WVD method to monitor a gas turbine [35], used for marine applications where an early fault detection can prevent a catastrophic failure. The WVD method analyses vibration amplitudes of the turbine components once-per-revolution. This method has been used in damage detection of the helicopter transmission [36]. It has been demonstrated that the WVD analysis of the signal average (with no filtering or enhancement) was able to reveal prior to the failure.

\subsection{Hilbert-Huang Transform}

This method is relatively new. It uses a combination of the Empirical Mode Decomposition and Hilbert-Huang Transform (HHT) methods [3940] to conduct an adaptive non-parametric timefrequency analysis. There are two main steps in HHT algorithm: the first is to compose a set of Intrinsic Mode Functions (IMF) by finding extrema (minimum and maximum values in a signal) and linking them with cubic splines and determining a mean value in the created envelope. The created trend is then subtracted from the original signal and repeated until stop criteria are met; the second step is to apply the Hilbert transform to each IMF which what allows the computation of the instantaneous frequency.

The EMD method cannot decompose a narrowband multi-harmonic signal and the first IMF can cover too wide range of the harmonics. These issues can be overcame by using adaptive band-pass filters and the Wavelet Packet Transform as pre-processors of the HHT [40]. The second problem is the mode mixing when a single IMF can cease to have a physical meaning by itself, suggesting falsely that there is a physical process in signal. To overcome this issue, it has been proposed to add the white noise to the signal to provide a uniform reference frame in the time-frequency space, thereby force to exhaust all possible solutions in the EMD sifting process. This method is called Ensemble Empirical Mode Decomposition [40].

The advantages of this method are algorithms simplicity and ability to deal with both nonstationary and nonlinear signals. Low computing requirement makes this method very suitable for online health monitoring of systems, which requires data to be processed in real time.

\subsection{Vibration monitoring summary}

In more advanced processing of vibration data, they can be decomposed in real time by the timefrequency analysis paving the path for detection of incipient faults before they develop into a failure. Vibration analysis can expose excessive wear and tear of internal machinery components.

Analysing vibration data of an engine requires both frequency and time domain [32]. Time localization is particularly important to detect phenomena of short duration and multi-frequency components that shift in time. For comprehensive "real-time" vibration analysis, it is worth to consider more than one method at the same time. For instance, the FFT algorithm can be effective in extracting frequencies with the highest vibration amplitudes while the shaft rotates at constant speed. As this analysis allows an easy correlation of frequencies and gas turbines' health (e.g. relation between the first harmonic frequency and the speed). On the other hand, the Wavelet Analysis and the HHT allow decomposing nonstationary signals which are dominant during changes in speed of an engine.

\section{CONCLUSION}

Research work focused on increasing both the availability and the reliability of rotating equipment has been done in the last couple of decades. In the early 1980 's, it was proposed to focus maintenance regimes on reactions rather than on predictions ("If it ain't broke, don't fix it") or time-based intervals. There has been extensive research done in order to understand processes of gas turbines' performance degradation and their causes, and how they can be predicted using GPA. Incipient faults, which can occur prior to a major system failure, can be isolated using a GPA or vibration analysis. A combination of different sensors used for registering such parameters as the vibration level of bearings and their temperatures can improve fault detection at an earlier stage than when it is done using only one sensor measurement. Data can be analysed by a pre-programmed expert algorithm that does the troubleshooting of a problem remotely. Advances in creating data acquisition 
systems, such as increased measurement resolutions and larger storage capacities in hard drives, at a little extra cost allow gathering vast amounts of data. This information can now be processed more rapidly with higher computing performance allowing a combination of different methods in order to minimise their drawbacks while combining their strengths.

\section{REFERENCES}

1. Jaw LC. Recent advancements in aircraft engine health management (EHM) technologies and recommendations for the next step. Proceedings of GT2005 ASME Paper GT 2005-68625. http://dx.doi.org/10.1115/GT2005-68625

2. Boyce MP, Meher-Homji CB, Wooldridge B. Condition monitoring of aeroderivative gas turbines. Gas Turbine and Aeroengine Congress and Exposition, Toronto, Ontario, Canada, 1989, ASME Paper No. 89-GT-36. http://dx.doi.org/10.1115/89GT-36

3. Tsalavoutas A, Aretakis N, Mathioudakis K, Stamatis A. Combining advanced data analysis methods for the constitution of an integrated gas turbine condition monitoring and diagnostic system. Proceedings of ASME Turbo Expo 2000, Munich, Germany. 2000, ASME Paper No 2000-GT-0034. http://dx.doi.org/10.1115/2000-GT-0034

4. Rausand M. Reliability centered maintenance. Reliability Engineering and System Safety 1998;60: 121-132. https://doi.org/10.1016/S09518320(98)83005-6

5. Diakunchak IS. Performance deterioration in industrial gas turbines, international gas turbine and aeroengine congress and exposition. Orlando, Florida, 1991, ASME Paper No 91-GT-228. https://doi.org/10.1115/91-GT-228

6. Kurz R, Brun K, Wollie M. Degradation effects on industrial gas turbines. ASME J. Eng. Gas Turbines Power. 2009; 131: 62401. https://doi.org/10.1115/1.3097135

7. Kurz R, Brun K. Gas Turbine Tutorial-Maintenance and Operating Practices Effects on Degradation and Life Proceedings of $36^{\text {th }}$ Turbomachinery Symposium, 2007. https://doi.org/10.21423/R15W7F

8. Wong M. L. D, Jack L. B, Nandi A. K. Modified selforganising map for automated novelty detection applied to vibration signal monitoring. Mechanical Systems and Signal Processing 20, 2006, 593-610. http://dx.doi.org/10.1016/j.ymssp.2005.01.008

9. Brotherton T, Jahns G, Jacobs J, Wroblewski D. Prognosis of faults in gas turbine engines. Aerospace Conference Proceedings. IEEE, 2000; 6:18-25163171. https://doi.org/10.1109/AERO.2000.877892

10. Chiang LH, Russell EL, Braatz RD. Fault detection and diagnosis in industrial systems. London, 2001. http://dx.doi.org/10.1007/978-1-4471-0347-9

11. Luo J, Namburu M, Pattipati K, Qiao L, Kawamoto M, Chigusa S. Model-based prognostic techniques, proceedings of the IEEE Autotestcon, 2003:330-340. http://dx.doi.org/10.1109/AUTEST.2003.1243596

12. Li YG, Nilkitsaranont P. Gas turbine performance prognostic for condition-based maintenance. Applied Energy 86, 2009, 2152-2161.

https://doi.org/10.1016/j.apenergy.2009.02.011
13. Mathioudakis K, Stamatis A, Tsalavoutas A, Aretakis N. Performance analysis of industrial gas turbines for engine condition monitoring. Proc. Inst. Mech. Eng., Part A. J. Power Energy. 2001;215(A2):173-184. https://doi.org/10.1243/0957650011538442

14. Stamatis A, Mathioudakis K, Papailiou KD. Adaptive simulation of gas turbine performance. ASME J. Eng. Gas Turbines Power. 1989;112:168-175. http://dx.doi.org/10.1115/1.2906157

15. Luppold RH, Roman JR, Gallops GW, Kerr LJ. estimating in flight engine performance variations using-kalman filter concepts. $25^{\text {th }}$ Joint Propulsion Conference, Joint Propulsion Conferences, 1989. http://dx.doi.org/10.2514/6.1989-2584

16. Cybenko G. Approximation by superpositions of a sigmoidal function, mathematics of control. Signals and Systems. 1989; 2(4):303-314, Springer. http://dx.doi.org/10.1007/BF02551274

17. Pong-Jeu L, Ming-Chuan Z, Tzu-Cheng H, Zhang J. An evaluation of engine faults diagnostics using artificial neural networks. J. Eng. Gas Turbines Power. 2000;123(2): 340-346. http://dx.doi.org/10.1115/1.1362667

18. Lazzaretto A, Toffolo A. Analytical and neural network models for gas turbine design and off-design simulation. Int. J. Appl. Thermodynam. 2001;4(4): 173-82.

19. Boccaletti C, Cerri G, Seyedan B. A neural network simulator of a gas turbine with a waste heat recovery section. ASME Turbo Expo 2000 Munich, Germany, May 8-11, 2000, ASME Paper No 2000-GT-0185. http://dx.doi.org/10.1115/2000-GT-0185

20. Dominiczak K, Rządkowski R, Radulski W, Szczepanik R. Online prediction of temperature and stress in steam turbine components using neural networks. J. Eng. Gas Turbines Power. 2016;138(5), ASME Paper No: GTP-15-1396.

http://dx.doi.org/10.1115/1.4031626

21. Kobayashi T, Simon DL. Hybrid neural-network genetic-algorithm technique for aircraft engine performance diagnostics. Journal of Propulsion and Power. 2005;21(4): 751-758. http://dx.doi.org/10.2514/1.9881

22. Kanelopoulos K, Stamatis A, Mathioudakis K, Incorporating Neural Networks into Gas Turbine Performance Diagnostics, 1997, ASME paper, 97GT-35. http://dx.doi.org/10.1115/97-GT-035

23. DePold HR, Gass FD. The application of expert systems and neural networks to gas turbine prognostics and diagnostics. Trans. ASME, J. Eng. Gas Turbines Power. 1999; 121: $607-612$. http://dx.doi.org/10.1115/1.2818515

24. Volponi AJ, DePold H, Ganguli R, Daguang C. The use of Kalman filter and neural network methodologies in gas turbine performance diagnostics: a comparative study. ASME Turbo Expo 2000 Munich, May 8-11, 2000, ASME Paper No. 2000-GT-0547. http://dx.doi.org/10.1115/1.1419016

25. Ogaji SOT, Singh R. Advanced engine diagnostics using artificial neural networks. Applied Soft Computing 3 (3), 2003, 259-271. http://dx.doi.org/10.1016/S1568-4946(03)00038-3

26. Yang X, Pang S, Shen W, Lin X, Jiang K, Wang Y. Aero engine fault diagnosis using an optimized extreme learning machine. International Journal of Aerospace Engineering. 2016, Article ID 789287. http://dx.doi.org/10.1155/2016/7892875

27. Palade V, Patton RJ, Uppal FJ, Quevedo J, Daley S. Fault diagnosis of an industrial gas turbine using 
neuro-fuzzy methods. IFAC Proceedings 2002;35(1): 471-476. http://dx.doi.org/10.3182/20020721-6-ES1901.01632

28. Verma R, Roy N, Ganguli R. Gas turbine diagnostics using a soft computing approach, Applied Mathematics and Computation. 2006; 172(2): 13421363. http://dx.doi.org/10.1016/j.amc.2005.02.057

29. Jardine AKS, Lin D, Banjevic D. A review on machinery diagnostics and prognostics implementing condition-based maintenance. Mechanical Systems and Signal Processing. 2006; 20(7): 1483-1510. http://dx.doi.org/10.1016/j.ymssp.2005.09.012

30. Poyhonen S, Jover P, Hyotyniemi H. Signal processing of vibrations for condition monitoring of an induction motor. First International Symposium on Digital Object Identifier. 2004: 499-502. http://dx.doi.org/10.1109/ISCCSP.2004.1296338

31. Al-Badour F, Sunar M, Cheded L. Vibration analysis of rotating machinery using time-frequency analysis and wavelet techniques. Mechanical Systems and Signal Processing 2011; 25(6): 2083-2101. http://dx.doi.org/10.1109/ISCCSP.2004.1296338

32. Peng ZK, Chu FL. Application of the wavelet transform in machine condition monitoring and fault diagnostics: a review with bibliography. Mechanical Systems and Signal Processing. 2004;18(2):199-221. http://dx.doi.org/10.1016/S0888-3270(03)00075-X

33. Aretakis N, Mathioudakis K. Wavelet analysis for gas turbine fault diagnostics. Journal of Engineering for Gas Turbines and Power 1997;119:870-6. http://dx.doi.org/10.1115/1.2817067

34. Feng Z, Liang M, Chu F, Recent advances in timefrequency analysis methods for machinery fault diagnosis: A review with application examples. Mechanical Systems and Signal Processing. 2013; 38(1):165-205. http://dx.doi.org/10.1016/j.ymssp.2013.01.017

35. Harrison GA, Koren I, Lewis M, Taylor FJ, Meltzera G, Dien NP. Application of wavelet and Wigner analysis to gas turbine vibration signal processing. Proceedings of SPIE on Wavelet Application. 1998; 3391:490-501. http://dx.doi.org/10.1117/12.304898

36. Samuel PD, Pines DJ. A review of vibration-based techniques for helicopter transmission diagnostics. Journal of Sound and Vibration. 2005; 282(1-2): 475-508. http://dx.doi.org/10.1016/j.jsv.2004.02.058

37. Meltzer G, Dien NP. Fault diagnosis in gears operating under non-stationary rotational speed using polar wavelet amplitude maps. Mechanical Systems and Signal Processing 2004;18(5):985-992. http://dx.doi.org/10.1016/j.ymssp.2004.01.009

38. Hee LM, Leong MS. Diagnosis for loose blades in gas turbines using wavelet analysis. J. Eng. Gas Turbines Power. 2005;127(2):314-322 http://dx.doi.org/10.1115/1.1772406

39. Leia Y, Hea Z, Zia Y, Hua Q. Fault diagnosis of rotating machinery based on multiple ANFIS combination with Gas. Mechanical Systems and Signal Processing. 2007;21(5):2280-2294. http://dx.doi.org/10.1115/1.1772406

40. Lei Y, Zuo MJ. Fault diagnosis of rotating machinery using an improved HHT based on EEMD and sensitive IMFs. Measurement Science and Technology, 2009;20:125701- 125712. http://dx.doi.org/10.1088/0957-0233/20/12/125701

41. Peng ZK, Tse PW, Chu FL. A comparison study of improved Hilbert-Huang transform and wavelet transform: Application to fault diagnosis for rolling bearing, Mechanical Systems and Signal Processing,
2004, 19: 974-988.

http://dx.doi.org/10.1016/j.ymssp.2004.01.006

42. Vachtsevanos G, Lewis FL, Roemer M, Hess A, Wu B. Intelligent fault diagnosis and prognosis for engineering systems, 2006.

http://dx.doi.org/10.1002/9780470117842

\section{Received 2018-01-09}

Accepted 2018-04-04

Available online 2018-04-09

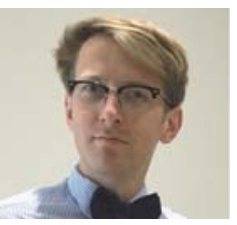

Marcin ADAMOWICZ, received M. Sc. Degree in Control Engineering from Gdańsk University of Technology in 2009. Now works in Solar Turbines S.A. as Field Service Representative. His current research interest includes Fault Detection Analysis, Signal Processing and Artificial Neural Networks.

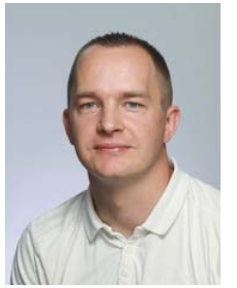

Grzegorz ŻYWICA, PhD, Eng. Since 2005 has been working at the Institute of Fluid Flow Machinery, Polish Academy of Sciences in Gdańsk. He is the Head of the Department of Turbine Dynamics and Diagnostics. His scientific work focuses on: computational simulation, designing of rotating machinery and bearing systems, rotor dynamics, modal analysis and technical diagnostics. 